\title{
Original article (short paper) \\ Concurrent fatigue and postactivation potentiation during extended interval training in long-distance runners
}

\author{
Pedro Ángel Latorre-Román \\ Felipe García-Pinillos \\ Emilio José Martínez-López \\ University of Jaen, Spain \\ Victor Manuel Soto-Hermoso \\ University of Granada, Spain
}

\begin{abstract}
The purpose of this study is to analyze acute effect of running extended interval training(EIT) on vertical jump (VJ) and handgrip strength (HS) performance in experienced endurance athletes. In order to analyze mechanical parameters of the VJ and HS between runs, sixteen experienced male athletes performed an EIT ( $4 \times 3 \times 400 \mathrm{~m})$. The results show that fatigue induced by EIT does not impair handgrip strength or VJ performance. A significant improvement $(p<$ $.05)$ was noted for $\mathrm{VJ}$ due to the postactivation potentiation (PAP) phenomenon. A positive correlation $(r=.619, p=$ .011) was found between VJ and lactate. The results suggest that experienced long-distance runners can maintain their strength levels and, consequently, work capacity, despite the induced fatigue by the field training demand. Therefore, $\mathrm{VJ}$ performance during EIT can be used as an indicator of muscular adaptations to training and, together, with handgrip strength, become indicators of fatigue. These indicators allow proper prescription training routines.
\end{abstract}

Keywords: countermovement jump, handgrip strength, endurance athletes, strength

Resumo - "Fadiga concorrente e potenciação pós-ativação durante o treinamento intervalado extensivo em corredores de fundo." O objetivo do estudo é analisar a relação entre a fadiga e a potenciação pós-ativação (PPA) nos corredores de fundo durante uma sessão de treinamento típico, extensivo treinamento intervalado (ETI). Dezesseis atletas experientes executaram o ETI $(4 \times 3 \times 400 \mathrm{~m})$ e se avaliou o desempenho entre as repetições e os parâmetros mecânicos associados ao salto vertical (SV) e à força de preensão manual. Os resultados mostram que o ETI não deteriora o desempenho dos atletas neste nesta prova e que inclusive há um aumento no SV $(p<0,05)$, devido ao fenômeno do PPA. Verificou-se uma correlação entre SV-lactado $(r=0,619, p=0,011)$. Os dados obtidos sugerem que os atletas de resistência podem manter os níveis de força e a capacidade de trabalho apesar de fadiga induzida por ETI. O desempenho no SV para um ETI pode ser indicador de adaptações musculares do treino que, junto com a força de preensão manual, podem ser utilizadas como ferramentas para prescrição de treinamento.

Palavras-chave: salto com contramovimento, força de preensão manual, atletas de resistência, força

Resumen- -Fatiga concurrente y potenciación postactivación durante el entrenamiento interválico extendido en corredores de resistencia." El objetivo del estudio el efecto de un entrenamiento interválico extensivo (EIE) en el rendimiento en salto vertical (SV) y dinamometría manual en corredores de resistencia. Dieciséis atletas experimentados ejecutaron el EIE (4x3x400m), y se evaluó entre repeticiones el rendimiento en SV y parametros mecánicos asociados, y en fuerza de prensión manual. Los resultados muestran que EIE no deteriora el rendimiento en dichos test, e incluso aumenta significativamente en SV $(p<0,05)$ debido al fenómeno de potenciación postactivación (PPA). Se halló correlación entre SV y lactato $(r=0,619 ; p=0,011)$. Los datos obtenidos sugieren que atletas de resistencia pueden mantener niveles de fuerza y capacidad de trabajo a pesar de la fatiga inducida por este entrenamiento en pista. El rendimiento en SV durante un EIE puede usarse como indicador de adaptaciones musculares al entrenamiento y, junto a fuerza de prensión manual, podrían utilizarse como herramientas para la prescripción del entrenamiento.

Palabras clave: salto con contramovimiento, fuerza de prensión manual, atletas de resistencia, fuerza 


\section{Introduction}

The term postactivation potentiation (PAP) refers to the phenomenon which significantly enhances muscle performance as a result of previous muscular work (Tillin \& Bishop, 2009). Proposed by Tillin and Bishop (2009), PAP can be explained by two mechanisms: increased recruitment of higher order motor units, and phosphorylation of myosin regulatory light chains. However, the mechanism responsible for muscle potentiation has not been fully explained, and acute changes in muscle architecture may also contribute to the PAP response (Reardon et al., 2014).

It is well known that the contractile history of a muscle has two opposing effects on muscular force output: PAP and fatigue. The relationship between PAP and fatigue is affected by several variables (Chatzopoulos et al., 2007) including, but not limited to, training experience (Kilduff et al., 2007), rest period length (Sapstead \& Duncan, 2013) and the type, intensity and volume of the conditioning activity performed (Sale, 2002). These variables have not been standardized in past research and, as a result, evidence of the effects of conditioning activity on the performance of subsequent explosive activities was found equivocal (Millet, Martin, Lattier, \& Ballay, 2003). Moreover, no consensus has been reached regarding the optimal acute conditioning mode protocol in athletic groups (Wilson et al., 2013).

In general, PAP is expected to occur after evoked contractions and after near-maximum or maximum voluntary conditioning activity. Indeed, the majority of previous studies have induced PAP through the use of maximal voluntary contractions (Mettler \& Griffin, 2012). However, after running to reach fatigue, power performance is not supposed to improve (Millet \& Lepers, 2004). Contrary to expectations, previous studies indicate that not only explosive, short and intense stimuli can be used as a conditioning activity, but also sub-maximum and prolonged exercises can cause PAP for subsequent activities (Boullosa, Tuimil, Alegre, Iglesias, \& Lusquiños, 2011; Vuorimaa, Virlander, Kurkilahti, Vasankari, \& Häkkinen, 2006). Therefore, Hamada, Sale, and MacDougall (2000) indicated that endurance training causes, on one hand, a greater amount of phosphorylation of regulatory myosin light chains in slow fibers and, on the other hand, a greater resistance to fatigue, which would lead to prevalence of PAP in endurance runners.

Considering these previous studies, there is no available consensus about the effects of specific-fatigue induced by running exercises on power performance in long-distance runners. Moreover, most of studies have been conducted in laboratory or maximum performance field tests. Thus, there are pending issues with regard the assessement of induced fatigue with a common workload in endurance athletes (extended interval training, EIT) performed during outdoor track field test, and the effects on muscular power of the involved muscles (countermovement jump, VJ), as well as those that are not involved (handgrip strength, HS). Therefore, the main purpose of this study is to analyze the acute effect of running exercises (EIT) on vertical jump and handgrip strength performance in experienced endurance athletes. We hypothesized that experienced long-distance runners would maintain their strength and power levels despite fatigue induced by a field training (EIT).

\section{Methods}

\section{Participants}

Sixteen experienced sub-elite male long-distance runners (age $=29.63 \pm 7.32$ years; body mass index, $\mathrm{BMI}=23.15 \pm$ 2.14; maximal oxygen uptake, $\mathrm{VO}_{2 \max }=56.9 \pm 3.05 \mathrm{ml} \cdot \mathrm{Kg}^{-1}$. $\mathrm{min}^{-1}$ ) with a minimum experience of six years of training and competition, participated voluntarily in this study. The athletes trained regularly and had no history of injury in the previous three months that limited training. After receiving detailed information on the purpose and procedure of the study, each athlete signed an informed consent for participation, which complied with the ethical standards of the World Medical Association Declaration of Helsinki (2008), approved by the Ethics Committee of the University of Jaen, Spain. Table 1 shows the socio-demographic characteristics and training experience of the participants.

\section{Procedures}

Participants were tested individually on two occasions. First, in a preliminary session, anthropometric assessment and familiarization with VJ and HS tests were carried out. Anthropometric parameters were: height (m) measured with a stadiometer (Seca 222, Hamburg, Germany), body mass $(\mathrm{kg})$ recorded with a Seca 634 (Hamburg, Germany), and body mass index (BMI) (BMI= body mass $[\mathrm{kg}] /$ height $\left[\mathrm{m}^{2}\right]$ ). During the first session, in order to estimate the $\mathrm{VO}_{2} \max$ (Léger, Mercier, Gadoury, \& Lambert, 1988), the Léger test required 20-meter sprints with increasing speed in each bout,

Table 1. Socio-demographic characteristics and training background of the participants $(n, \%)$.

\begin{tabular}{lcc}
\hline \multicolumn{2}{l}{ Socio-demographic/training characteristics } & $\boldsymbol{n}(\mathbf{\%})$ \\
\hline \multirow{2}{*}{ Academic level } & Primary & $2(12.5)$ \\
& Secondary & $10(62.5)$ \\
& University & $4(25.0)$ \\
Married & No & $7(43.8)$ \\
& Yes & $8(50.0)$ \\
Laboral activity & Separated & $1(6.3)$ \\
& In work & $12(75.0)$ \\
Training experience (years) & Unemployed & $4(25.0)$ \\
\hline \multirow{2}{*}{ Perceived fitness state } & 6 to 8 & $4(2.5 .0)$ \\
& 8 to 12 & $10(62.5)$ \\
Numbers of training sessions & More than 12 & $2(12.5)$ \\
weekly & $60 \%$ to $79 \%$ & $8(50.0)$ \\
\hline \multirow{2}{*}{ Trainer } & $80 \%$ to $100 \%$ & $8(50.0)$ \\
\hline
\end{tabular}


with rhythm paced with audible signal. $\mathrm{VO}_{2 \max }$ was calculated based on the participant reached speed in the last sprint using the following equation: $\mathrm{VO}_{2}\left(\mathrm{ml}^{-K^{-1}} \mathrm{~min}^{-1}\right)=5.857 \mathrm{x}$ velocity $\left(\mathrm{km} \cdot \mathrm{h}^{-1}\right)-19.458$.

The second session took place 7 days after the preliminary session in an outdoor running track field (lane 1) (temperature $=17.16 \pm 5.81{ }^{\circ} \mathrm{C}$; relative air humidity $=62.65 \pm 16.06 \%$ ). Participants were instructed to avoid strenuous exercise 72 hours before the training protocol. Before EIT, the athletes performed a warm-up, which consisted of 5-10 minutes of continuous running at a comfortable speed and 10 minutes of general exercises. Then (pretest, non fatigue condition), participants performed three VJs, separated by a 15 -second recovery interval, which were later averaged, and two trials of a 3-second HS, with n interval of 15-second recovery. Average results from both hands were calculated. Next, the participants began the EIT protocol, which consisted of 12 runs of 400 meters, grouped into 4 sets of 3 runs, with 1-minute passive recovery between runs, and three-minute between sets $(4 \times 3 \times 400 \mathrm{~m})$. Interval training widespread is used in the physical preparation of almost all endurance athletes (Gorostiaga et al., 2010), and characterizes exertion lasting 60 to 90 seconds with $85-100 \%$ intensity of maximal aerobic speed with high volume of exercise bouts.

Between each $400 \mathrm{~m}$ running bout, the Borg Rating of Perceived Exertion Scale (RPE) (Borg, 1982) was recorded together with HRpeak and HRrec, using the Garmin Forerunner monitor 405 (Kansas, USA), time spent in each $400 \mathrm{~m}$ run $\left(\mathrm{T}_{400 \mathrm{~m}}\right)$, and the HS of both hands (under identical conditions as those in the pretest). Moreover, between each set, the VJ and blood lactate were also measured. The VJ performance was recorded 2 minutes after the end of the last conditioning stimulus (the last 400 $\mathrm{m}$ of each set), or VJ performance in fatigued condition (set1, set2, set3, and set4). The VJ was performed under identical conditions to the pretest (three jumps separated by 15 seconds, with average of three trials). Blood lactate was recorded after the last running of each bout and for this purpose, a portable lactate analyzer Lactate-Pro (blood lactate $=\mathrm{mmol} \cdot \mathrm{l}^{-1}$; Arkray, Inc.) was used. The measured time employed in each set was the average of the three runs $\left(\mathrm{T}_{400 \mathrm{~m}}\right)$.

During VJ participants were required to flex their knees in a 90 degrees angle. Participants are experienced athletes who perform VJ in their daily training sessions. Moreover, to make sure the execution of the VJ was correct, a familiarization session was carried out previously. The VJ was recorded using the FreePower Jump Sensorize (Biocorp, Italy) device, which was previously validated (Picerno, Camomilla, \& Capranica,
2011), and follows the following parameters (averaged from three trials): maximum jump height $(\mathrm{cm})$, peak velocity $\left(\mathrm{P}_{\text {velocity }}\right.$; $\left.\mathrm{m}^{-1}\right)$, flight time $\left(\mathrm{F}_{\text {time }} ; \mathrm{s}\right)$, peak force $\left(\mathrm{P}_{\text {force }} ; \mathrm{N} \cdot \mathrm{kg}^{-1}\right)$, peak power $\left(\mathrm{P}_{\text {power }} ; \mathrm{W} \cdot \mathrm{kg}^{-1}\right)$, eccentric work $\left(\mathrm{EccW} ; \mathrm{J}^{\mathrm{kg}}{ }^{-1}\right)$ and concentric work (ConcW; $\mathrm{J}^{\mathrm{kg}}{ }^{-1}$ ). External mechanical work was calculated using the variation of instantaneous total mechanical energy of the centre of mass (Cavagna, 1975).

The HS test was performed considering the recommendations of previous studies (Ruiz et al., 2006). To record the HS $(\mathrm{kg})$, a digital hand dynamometer was used (TKK 5101 Grip D; Takey, Tokyo Japan), adjusting the optimum grip through the calibration formula of Ruiz et al. (2006). Participants were encouraged to achieve maximum HS.

\section{Data analyses}

The data were analyzed using the statistics program SPSS 20.0 for Windows (SPSS Inc, Chicago, USA) and the significance level was set at $p<.05$. The data are shown as descriptive statistics of mean and standard deviation. We used the Shapiro-Wilk test to verify normal distribution of data. The comparison of data between $400 \mathrm{~m}$ runs was performed using a repeated-measures analysis (ANOVA). We performed the non -parametric contrast test of Friedman and Wilcoxon for those data in which no normal distribution was achieved after several transformations (square root transformation and logarithmic), and we determined the Pearson correlation of variables between the increase from the first to the last sets.

\section{Results}

Table 2 shows the results of the different repeated measures for the fatigue variables (lactate, $\mathrm{HR}_{\text {peak }}, \mathrm{HR}_{\mathrm{rec}}$ and RPE). All variables show a significant increase $(p<.001)$ throughout the training protocol.

Performance variables analyzed throughout the EIT, $\mathrm{T}_{400 \mathrm{~m}}$, $\mathrm{VJ}, \mathrm{F}_{\text {time, }}, \mathrm{P}_{\text {force }}$ and $\mathrm{P}_{\text {power }}$ changed significantly $(p<.05)$, while other mechanical parameters of VJ $\left(\mathrm{P}_{\text {velocity }}\right.$ EccW and ConcW) remained unchanged $(p \geq .05)$. The HS performance showed no significant increase throughout the training session $(p \geq .05)$.

Pearson correlation between the different variables showed that $\Delta$ lactate correlated with $\Delta \mathrm{VJ}(r=.619 ; p=.011)$ (Figure 1), $\Delta \mathrm{P}_{\text {velocity }}(r=.594, p=.015), \Delta$ ConcW $(r=.533, p=.033)$, with flight time $\left(\Delta \mathrm{F}_{\text {time }}\right)(r=.507,=.045)$, and with $\Delta \mathrm{T}_{400 \mathrm{~m}}(r=-.566$,

Table 2. The evolution of results obtained from fatigue variables analyzed (lactate, $\mathrm{HR}_{\text {peak }}$, $\mathrm{HR}_{\mathrm{rec}}$ and RPE) during EIT protocol, and the comparisons made post-hoc (mean, SD).

\begin{tabular}{lccccc}
\hline & Set 1 & Set 2 & Set 3 & Set 4 & p-values \\
\hline Lactate $(\mathrm{mmol} / \mathrm{l})$ & $10.49(2.22)^{\mathrm{a}}$ & $11.86(2.6)^{\mathrm{ab}}$ & $12.88(3.11)^{\mathrm{b}}$ & $13.00(2.59)^{\mathrm{b}}$ & $<.001$ \\
$\mathrm{HR}_{\text {peak }}(\mathrm{bpm})$ & $176.12(8.1)^{\mathrm{a}}$ & $178.65(9.73)^{\mathrm{b}}$ & $180.4(8.98)^{\mathrm{c}}$ & $182.48(9)^{\mathrm{d}}$ & $<.001$ \\
$\mathrm{HR}_{\text {rec }}(\mathrm{bpm})$ & $133.18(8.84)^{\mathrm{a}}$ & $143.18(10.4)^{\mathrm{b}}$ & $149.2(12.54)^{\mathrm{c}}$ & $152.9(12.3)^{\mathrm{d}}$ & $<.001$ \\
${\text { RPE }(6-20)^{*}}^{\mathrm{d}}$ & $15.06(1.49)^{\mathrm{a}}$ & $16.44(1.34)^{\mathrm{b}}$ & $17.41(1.00)^{\mathrm{c}}$ & $18.19(1.05)^{\mathrm{d}}$ & $<.001$ \\
\hline
\end{tabular}

*Friedman's test; Values with different upper letters indicate significant differences $(p<.05)$; SD: standar deviation; $\mathrm{HR}_{\text {peak }}: \mathrm{Heart} \mathrm{rate} \mathrm{peak;} \mathrm{HR}_{\text {rec }}$ : recovery heart rate (1 minute post-exercise); RPE: rate of perceived exertion; bpm: beats per minute. 
Table 3. The evolution of results obtained from performance variables analyzed $\left(\mathrm{T}_{400 \mathrm{~m}}, \mathrm{VJ}, \mathrm{P}_{\text {force }}, \mathrm{P}_{\text {power }}, \mathrm{P}_{\text {velocity }}, \mathrm{F}_{\text {time }}, \mathrm{EccW}\right.$, ConcW and $\left.\mathrm{HS}\right)$ during EIT protocol, and the comparisons made post-hoc (mean, SD).

\begin{tabular}{|c|c|c|c|c|c|c|}
\hline & Rest & Set 1 & Set 2 & Set 3 & Set 4 & p-values \\
\hline $\mathrm{T}_{400 \mathrm{~m}}(\mathrm{~s})^{*}$ & -- & $77.06(7.22)^{\mathrm{a}}$ & $78.19(6.7)^{\mathrm{ab}}$ & $79.19(7.39)^{\mathrm{b}}$ & $79.19(7.02)^{\mathrm{ab}}$ & .015 \\
\hline $\mathrm{VJ}(\mathrm{cm})$ & $38.63(4.87)^{\mathrm{a}}$ & $41.03(4.26)^{\mathrm{b}}$ & $39.94(4.45)^{\mathrm{ab}}$ & $40.86(4.93)^{\mathrm{ab}}$ & $39.45(4.95)^{\mathrm{ab}}$ & .043 \\
\hline $\mathrm{F}_{\text {time }}(\mathrm{s})$ & $0.51(0.02)^{\mathrm{a}}$ & $0.53(0.02)^{\mathrm{b}}$ & $0.52(0.02)^{\mathrm{ab}}$ & $0.52(0.02)^{\mathrm{ab}}$ & $0.51(0.03)^{\mathrm{ab}}$ & $<.001$ \\
\hline $\mathrm{P}_{\text {velocity }}\left(\mathrm{m} \cdot \mathrm{s}^{-1}\right)$ & $2.37(0.18)$ & $2.47(0.13)$ & $2.42(0.12)$ & $2.40(0.27)$ & $2.40(0.15)$ & .248 \\
\hline $\mathrm{P}_{\text {force }}\left(\mathrm{N} \cdot \mathrm{kg}^{-1}\right)$ & $13.58(3.70)^{\mathrm{a}}$ & $14.77(3.66)^{\mathrm{ab}}$ & $15.06(3.93)^{\mathrm{ab}}$ & $15.80(3.5)^{\mathrm{b}}$ & $16.02(4.3)^{\mathrm{b}}$ & $<.001$ \\
\hline $\mathrm{P}_{\text {power }}\left(\mathrm{W} \cdot \mathrm{kg}^{-1}\right)$ & $25.23(6.56)$ & $27.98(5.37)$ & $28.06(5.5)$ & $28.77(5.74)$ & $29.00(5.78)$ & .004 \\
\hline $\operatorname{EccW}\left(\mathrm{J} \mathrm{kg}^{-1}\right)$ & $2.65(0.71)$ & $2.58(0.65)$ & $2.43(0.51)$ & $2.41(0.58)$ & $2.34(0.61)$ & .089 \\
\hline ConcW $\left(\mathrm{J}^{\mathrm{kg}}{ }^{-1}\right)$ & $6.44(0.95)$ & $6.65(0.79)$ & $6.32(0.56)$ & $6.4(0.82)$ & $6.22(0.83)$ & .118 \\
\hline HS (Kg) & $42.10(6.78)$ & $43.68(6.85)$ & $43.5(7.29)$ & $43.5(7.75)$ & $43.52(8.49)$ & .185 \\
\hline
\end{tabular}

*Friedman's test; Values with different upper letters indicate significant differences $(p<.05)$; SD: standar deviation; $\mathrm{T}_{400 \mathrm{~m}}$ : time spent in the 400 m run; VJ: countermovement jump; $\mathrm{F}_{\text {time }}$ : Flight time; $\mathrm{P}_{\text {velocity: }}$ peak velocity; $\mathrm{P}_{\text {force: }}$ peak force $\mathrm{P}_{\text {power }}$ : peak power; EccW: eccentric work; ConcW: concentric work; HS: handgrip strength.

$p=.022) . \Delta \mathrm{VJ}$ correlated with $\Delta \mathrm{P}_{\text {velocity }}(r=.969, p<.001)$, with the increase in peak power $\left(\Delta \mathrm{P}_{\text {power }}\right)(r=.524, p=.037), \Delta$ ConcW $(r=.728, p=.001)$, and with $\Delta \mathrm{F}_{\text {time }}(r=.823, p=.000)$.

The polynomial contrasts of $\mathrm{VJ}$ show a quadratic function fit $(p=.003), \mathrm{P}_{\text {velocity }}(p=.026)$ and $\mathrm{F}_{\text {time }}(p=.001)$ relative to the training protocol. Peak force $\left(\mathrm{P}_{\text {force }}\right)$ fitted to a linear function $(p<.001)$ and $\mathrm{P}_{\text {power }}(p=.009)$, which increased throughout the training protocol. However, EccW manifested an equally linear relation $(p=.032)$, but decreased in relation to the training protocol. The data according to ConcW show that there is fourth-order polynomial function fit $(p=.012)$. Figure 2 shows the profiles of these data.

\section{Discussion}

The main finding of this study is that VJ and HS performances are maintained, despite induced fatigue by EIT in long- distance runners. The athletes increased their VJ performance between resting interval and set 1 . Therefore, the presence of PAP in a field test based on the classic intermittent training protocol must be part of the main outcome of current study. The athletes carried out the training protocol according to the required intensity criteria. The evolution in the parameters indicative of fatigue show its increase throughout the training, reaching very high intensity levels $\left(\mathrm{RPE}=18.19 \pm 1.05 ; \mathrm{HR}_{\text {peak }}=182.48 \pm 9 \mathrm{bpm}\right.$; $\mathrm{HR}_{\text {rec }}=152.9 \pm 12.3 \mathrm{bpm}$; and Lactate $\left.=13 \pm 2.59 \mathrm{mmol} / \mathrm{l}\right)$.

In the present study, VJ performance improved between the resting condition (no fatigue) and the first set, with no differences in the remaining sets. This improvement is based

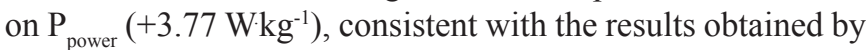
other researchers (Boullosa \& Tuimil, 2009; Boullosa et al., 2011). The $P_{\text {force }}$ shows significant improvements from the nonfatigued condition and the last 2 sets $\left(+2.22\right.$ and $\left.+2.44 \mathrm{~N} \cdot \mathrm{kg}^{-1}\right)$. The phenomenon of PAP allowed the loss of EccW and ConcW to be counteracted with an increase in $\mathrm{P}_{\text {force }}$ and $\mathrm{P}_{\text {power }}$, thus the



Figure 1. Regression showing the increase in lactic acid and VJ from the first to the last sets. VJ: countermovement jump. 
3A

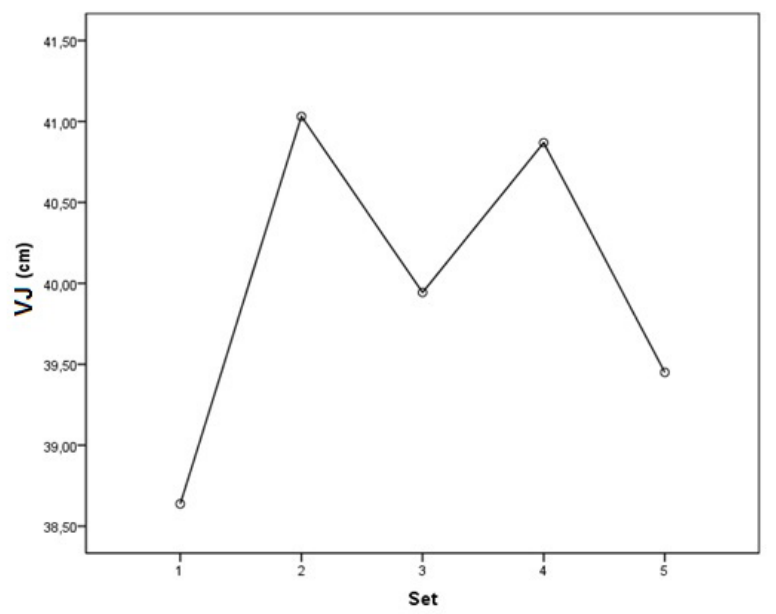

3C

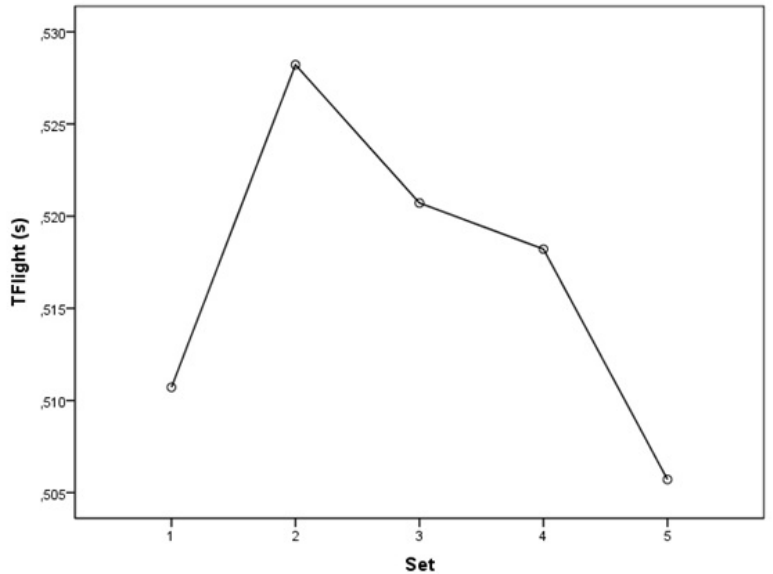

3D



3B

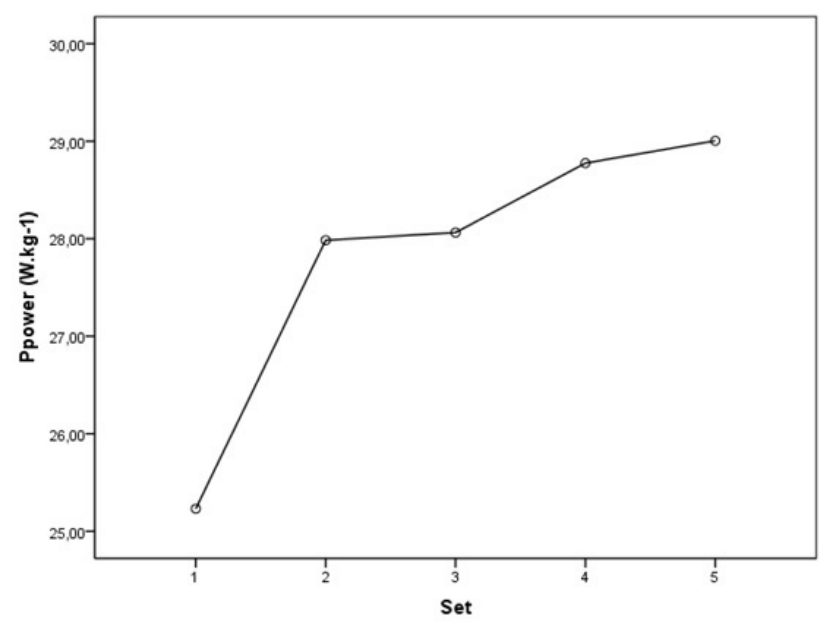

$3 \mathrm{C}$

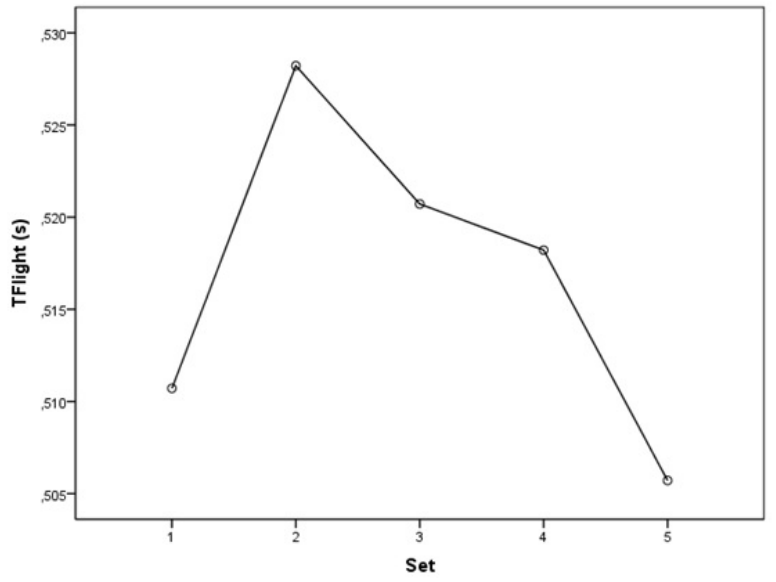

$3 F$

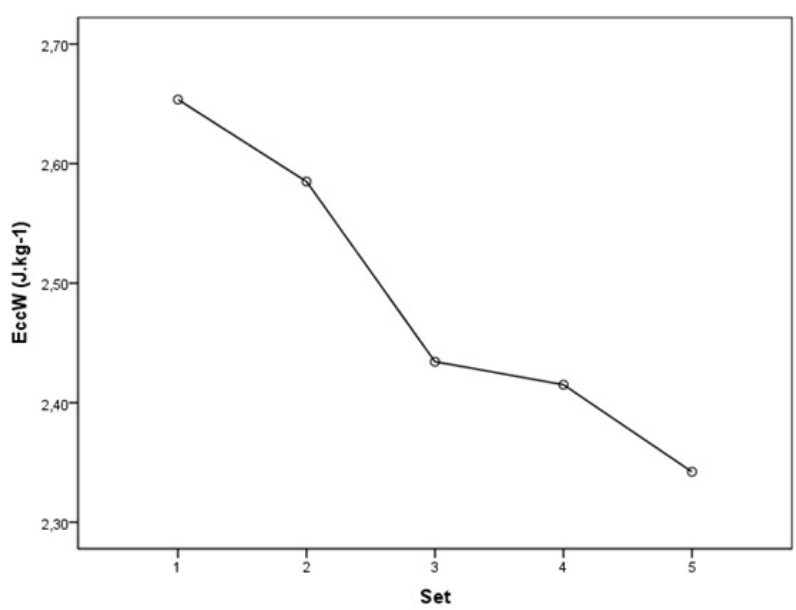

Figure 2. Profiles of results obtained in every measurements (rest, set1, set2, set3, and set4) for countermovement jump (VJ, 3A), peak power (Ppower, 3B), fligth time (Ftime, 3C), peak force (Pforce, 3D), peak velocity (Pvelocity, 3E), eccentric work (EccW, 3F), and concentric work (ConcW, 3F)

VJ performance is greater when $\mathrm{P}_{\text {force }}$ and when $\mathrm{P}_{\text {power }}$ are also greater (Boullosa \& Tuimil, 2009; Boullosa et al., 2011). In contrast, other authors (Vuorimaa et al., 2006) indicated that $\mathrm{P}_{\text {force }}$ decreases with increasing cumulative workload, but they concluded that the loss of force is compensated for by changes in the level of coordination and other neuromuscular mechanisms that make PAP possible - such as coactivation of synergist muscles that can occur under high load conditions and increases with the duration of exercise (Gandevia, 2001).
Over recent years, numerous studies have focused on the PAP phenomenon in different conditions, mainly, in sprint or vertical jump abilities after exercises with external loads or resistance (Chatzopoulos et al., 2007; Hamada et al., 2000; Skof \& Strojnik, 2006; Wilson et al., 2013). However, a limited number of studies have investigated running exercises (EIT) eliciting PAP in explosive movements such as VJ. Chatzopoulos et al. (2007) and Jimenez-Reyes, Cuadrado, and González-Badillo (2011) observed a PAP effect on running speed using work 
with an external load as a prior stimulus. In the same direction, other authors (Boullosa \& Tuimil, 2009; Boullosa et al., 2011; Vuorimaa et al., 2006) found PAP in VJ after different types of run. However, Parry et al. (2008) found no such potentiation in performance in a maximal effort test using a cycle ergometer exercise at very high intensity. Therefore, current research contributes to the PAP phenomenon during performance of specific skills such as vertical jump, during actual and widespread field training session (EIT) by long-distance runners.

Improvement in muscular strength performance in the present study is a surprising finding considering that fatigue is associated with impaired neuromuscular performance of leg muscles (Millet \& Lepers, 2004; Rassier \& Macintosh, 2000). This type of adaptation may be due to adaptive changes that occur in the nervous system in response to training. Electromyography studies have indicated adaptation mechanisms that may contribute to increased efferent neuronal outflow induced by training, including increased maximum firing frequency and excitability, and decreased pre-synaptic inhibition of spinal motor neurons (Aagard, 2003).

The correlation between $\Delta$ lactate and $\Delta \mathrm{VJ}(r=.619, p=$ $.011)$ is also worth noting. As indicated in the study by Skof and Strojnik (2006), PAP is possible despite high concentrations of lactate, and this study confirms that rationale. These results support those obtained by other researchers (Jiménez-Reyes et al., 2011) who observed that participants who tended to jump higher were those who were also able to accumulate more lactate. Vuorimaa et al. (2006) obtained different results for the correlation between $\Delta$ lactate and $\Delta \mathrm{VJ}$ according to the running protocol carried out: a positive correlation in the intermittent running protocol $(100 \%$ velocity associated with $\left.\mathrm{VO}_{2 \max }\right)(r=.62, p<.01)$ and a lack of correlation in continuous running $\left(80 \%\right.$ velocity associated with $\left.\mathrm{VO}_{2 \max }\right)$, although the improvements in VJ are significant $(p<.001)$ before and after both exercises. Similar findings where VJ increases or remains at the same level have been demonstrated during the early stages of an intermittent anaerobic test where blood lactate levels increased significantly above resting levels, but not at maximum levels (Paavolainen, Nummela, Rusko, \& Hakkinen, 1999). Therefore, in intermittent running, the increase in the intensity of the exercise and blood lactate concentration appears to be associated with greater explosive force in longdistance runners. Nevertheless, numerous contrasting views exist regarding the physiological effects of lactate and its roles postproduction. On the one hand, there is a clear association between the production of lactate and muscular fatigue (Facey, Irving, \& Dilworth, 2013). Muscle is considered a consumer of lactate (Facey et al., 2013; Gladden, 2000). The rate at which lactate is used is dependent on the rate of metabolism, blood flow, lactate concentration, hydrogen ion concentration, fiber type, and exercise training (Gladden, 2000), which leads the researchers to believe that more research is needed to check whether some of these parameters could explain the presence or absence of PAP in athletes of similar level.

Relative to the factors which determine the existence of PAP, relevant studies indicate that the optimal recovery time between prior conditioning stimulus and the subsequent action should be taken into account (Chatzopoulos et al., 2007; Kilduff et al., 2007), as well as the level of the athlete's strength and experience in training (Rassier \& Macintosh, 2000). Considering the recovery time between the conditioning stimulus and VJ, it should be emphasized that previous studies (Chatzopoulos et al., 2007; Kilduff et al., 2007) suggest that for potentiation to occur and to offset the effects of fatigue at least 5 minutes recovery time is required. In this study, $\mathrm{VJ}$ were performed in the second minute of recovery between the last conditioning stimulus of each sets (the last run of $400 \mathrm{~m}$ ) since that was the time resulting from the previous measurement of blood lactate, RPE and HS. Moreover, in effect, we expected that complete recovery of phosphocreatine resynthesis would be achieved in the second minute of recovery in endurance-trained runners (McMahon \& Jenkins, 2002). With this recovery and accumulated fatigue, PAP is obtained between non fatigue (rest) and set $1(+2.4 \mathrm{~cm}, p<.043)$.

Finally, another important result refers to the maintenance of HS performance throughout training sessions, even though it showed a non significant improvement after set $1(+1.58$ $\mathrm{kg}$ ) - which was maintained during the assessment protocol, despite accumulated fatigue. These data indicate the importance of central mechanisms in maintaining a certain level of force (Davis \& Fitts, 2001). Central fatigue induced by exercise is manifested by a decrease in muscle activation (Gandevia, 2001), and, in this regard, the decreased muscular force of muscles not involved in the exercise (HS) reveals supraspinal fatigue (Millet \& Lepers, 2004). A few previous studies have focused on this topic (Martin et al., 2010; Millet et al., 2003; Place, Lepers, Deley, \& Millet, 2004; Racinais, Girard, Micaleff, \& Perrey, 2007). Place et al. (2004), in order to check whether supraspinal fatigue occurs after prolonged exercise, noted the absence of changes in the force of muscles not involved in a prolonged running exercise through measuring HS. In this line, previous works (Millet \& Lepers, 2004; Racinais et al., 2007) provide similar data indicating that grip strength does not change significantly during continuous or intermittent exercise. The data obtained in the present study, joined to the previous studies, leading the authors to conclude that supraspinal fatigue did not occur in this type of exercise. However, this is a controversial topic and some researches (Martin et al., 2010; Millet et al., 2003) concluded an impairment of maximum voluntary activation in prolonged efforts. Just as indicated Racinais et al. (2007) this suggests that the ability of the central nervous system to activate muscle to the maximum may be altered only in continuous exercise (Racinais et al., 2007). In line with some authors (Millet \& Lepers, 2004), we find it convenient to make this simpler type of measure to explore the possible existence of supraspinal fatigue after endurance exercise and its relationship to the PAP phenomenon.

\section{Conclusion}

The results obtained suggest that experienced long-distance runners do not impair their VJ performance or HS during EIT, even increasing the vertical jump ability (PAP) 
in fatigue condition. Endurance athletes can maintain their strength levels and, consequently, work capacity, despite of induced fatigue by this field training protocol. Therefore, from a practical point of view, VJ performance during EIT can be used as an indicator of muscular adaptations to training and, together with HS, becomes an indicator of fatigue enabling the proper training routines to be prescribed. PAP obtained in this study has a mechanical explanation, but neither the molecular basis and neuromuscular parameters were explored. Finally, the PAP responses are different in each subject and it would be advisable for these tasks to be individualized, with an individualized rest for each subject as suggested by different authors. Additional studies may need to address these issues for a better and deeper understanding of this phenomenon during sports training.

\section{References}

Aagaard, P. (2003). Training-induced changes in neural function. Exercise Sport Science Review, 3, 61-67.

Boullosa, D.A., \& Tuimil, J.L. (2009). Postactivation potentiation in distance runners after two different field running protocols. Journal Strength Conditioning Research, 23, 1560-1565.

Boullosa, D.A., Tuimil, J.L., Alegre, L.M., Iglesias, E., \& Lusquiños, F. (2011). Concurrent fatigue and potentiation in endurance athletes. International Journal and Sports Physiology and Performance, 6, 82-93.

Borg, G.A. (1982). Psychophysical bases of perceived exertion. Medicine and Science in Sports and Exercise, 14, 377-381.

Cavagna, G.A. (1975). Force platforms as ergometers. Journal of Applied Physiology, 39, 174-179.

Chatzpoulos, D.E., Michailidis, C.J., Giannakos, A.K., Alexiou, K.C., Patikas, D.A., Antonopoulos, C.B., \& Kotzamanidis, C.M. (2007). Postactivation potentiation effects after heavy resistance exercise on running speed. Journal of Strength \& Conditioning Research, 21, 1278-1281.

Davis, M., \& Fitts, R. (2001). Mechanisms of muscular fatigue. In P. Darcey (Ed), ACSM'S resource manual - guidelines for exercise testing and prescription (pp 184-190).

Facey, A., Irving, R., \& Dilworth, L. (2013). Overview of lactate metabolism and the implications for athletes. American Journal of Sport Science and Medicine, 3, 42-46.

Gandevia, S.C. (2001). Spinal and supraspinal factors in human muscle fatigue. Physioogy Review, 81, 1725-1789.

Gladden, L.B. (2000). Muscle as a consumer of lactate. Medicine and Science in Sports and Exercise, 32, 764-771.

Gorostiaga, E.M., Asiain, X., Izquierdo, M., Postigo, A., Aguado, R., Alonso, J.M., \& Ibáñez, J. (2010). Vertical jump performance and blood ammonia and lactate levels during typical training sessions in elite $400 \mathrm{~m}$ runners. Journal of Strength and Conditioning, 24, 138-140.

Hamada, T., Sale, D.G., \& MacDougall, J.D. (2000). Postactivation potentiation in endurance-trained male athletes. Medicine Science Sports Exercise, 32, 403-411.

Jiménez-Reyes, P., Cuadrado, V., \& González-Badillo, J.J. (2011). Application of the CMJ Test to monitor training load in sprint sessions. Cultura, ciencia y deporte, 7, 105-112.

Kilduff, L.P., Bevan, H.R., Kingsley, M.C., Owen, N.J., Bennett, M.A., Bunce, P.J., \& Cunningham, D.J. (2007). Postactivation potentiation in professional rugby players: optimal recovery. Journal of
Strength \& Conditioning Research, 21, 1134-1138.

Léger, L.A., Mercier, D., Gadoury, C., \& Lambert, J. (1988). The multistage 20 metre shuttle run test for aerobic fitness. Canadian Journal Applied Sport Sciences, 6, 93- 101.

Martin, V., Kerherve, H., Messonier, L.A., Banfi, J.C., Geyssant, A., Bonnefoy, R., Feasson, L., \& Millet, G. Y. (2010). Central and peripheral contributions to neuromuscular fatigue induced by a 24-h treadmill run. Journal Applied Physiology, 108, 1224-1233.

McMahon, S., \& Jenkins, D. (2002). Factors affecting the rate of phosphocreatine resynthesis following intense exercise. Sports Medicine, 32, 761-784.

Mettler, J.A., \& Griffin, L. (2012). Postactivation potentiation and muscular endurance training. Muscle Nerve, 43, 416-425.

Millet, G.Y., Martin, V., Lattier, G., \& Ballay, Y. (2003). Mechanisms contributing to knee extensors strength loss after prolonged running exercise. Journal Applied Physiology, 94, 193-198.

Millet, G.Y., \& Lepers, R. (2004). Alterations of neuromuscular function after prolonged running, cycling and skiing exercises. Sports Medicine, 34, 105-116.

Paavolainen, L., Nummela, A., Rusko, H., \& Häkkinen, K. (1999). Neuromuscular characteristics and fatigue during $10 \mathrm{~km}$ running. International Journal of Sports Medicine, 20, 1-6.

Parry, S., Hancock, S., Shiells, M., Passfield, L., Davies, B., \& Baker, J.S. (2008). Physiological Effects of Two Different Postactivation Potentiation Training Loads on Power Profiles Generated During High Intensity Cycle Ergometer Exercise. Research in Sports Medicine, 16, 56-67.

Place, N., Lepers, R., Deley, G., \& Millet, G.Y. (2004). Time course of neuromuscular alterations during a prolonged running exercise. Medicine Sciences Sports Exercises, 36, 1347-1356.

Picerno, P., Camomilla, V., \& Capranica, L. (2011). Countermovement jump performance assessment using a wearable 3D inertial measurement unit. Journal of Sports Science, 29, 139-146.

Racinais, S., Girard, O., Micaleff, J.P., \& Perrey, S. (2007). Failed excitability of spinal motoneurons induced by prolonged running exercise. Journal of Neurophysiology, 97, 596-603.

Rassier, D.K., \& Macintosh, B.K. (2000). Coexistence of potentiation and fatigue in skeletal muscle. Brazilian Journal of Medical and Biological Research, 33, 499-508.

Reardon, D., Hoffman, J.R., Mangine, G.T., Wells, A.J., Gonzalez, A.M., Jajtner, A.R., ... Fukuda, D.H. (2014). Do Changes in Muscle Architecture Affect Post-Activation Potentiation? Journal of Sports Science and Medicine, 13(January), 483-492.

Ruiz, J.R., España-Romero, V., Ortega, F.B., Sjostrom, M., Castillo, M.J., \& Gutierrez, A. (2006). Hand span influences optimal grip span in male and female teenagers. Journal Hand Surgery, 31, 1367-72.

Sale, D.G. (2002). Postactivation potentiation: Role in human performance. Exercise and Sport Sciences Review, 30, 138-143.

Skof, B., \& Strojnik, V. (2006). Neuromuscular fatigue and recovery dynamics following prolonged continuous run at anaerobic threshold. British Journal of Sports Medicine, 40, 219-222.

Sapstead, G., \& Duncan, M.J. (2013). Acute effect of isometric midthigh pulls on postactivation potentiation during streth-shortening cycle and non-stretch-shortening cycle vertical jumps. Medicine in Sport, 17, 7-12.

Tillin, N.A., \& Bishop, D. (2009). Factors modulating post-activation potentiation and its effect on performance of subsequent explosive activities. Sports Medicine, 39, 147-166.

Vuorimaa, T., Virlander, R., Kurkilahti, P., Vasankari, T., \& Häkkinen, K. (2006). Acute changes in muscle activation and leg extensión performance after different running exercises in elite long distance runners. European Journal of Applied Physiology, 96, 282-291. 
Wilson, J.M., Duncan, N.M., Marin, P.J., Brown, L.E., Loenneke, J.P., Wilson, S.M.C., \& Ugrinowitsch, C. (2013). Metaanalysis of postactivation potentiation and power: Effects of conditioning activity, volume, gender, rest periods, and training status. Journal of Strength and Conditioning Research, 27, 854-859.

\section{Authors' note}

Pedro Ángel Latorre-Román (platorre@ujaen.es), Felipe García-Pinillos (fegarpi@gmail.com), and Emilio José Martínez-López (emilioml@ujaen.es) are affiliated with the University of Jaen, Department of Health Sciences. Campus de Las Lagunillas s/n. D2 Building, Dep. 142. 23071 Jaen (Spain).

Victor Manuel Soto-Hermoso is affiliated with the University of Granada, Department of Sports Sciences. Carretera de Alfacar s/n. 18071 Granada (Spain).

\section{Acknowledgements}

This study received no financial support. However, we would like to thank the company "Ergonomics Solei" for their support and guidance and also to all those athletes who contributed disinterestedly in this research.

\section{Corresponding author}

Felipe García-Pinillos, University of Jaen, Campus de Las Lagunillas s/n. D2 Building, Dep. 142. 23071, Jaén (Spain).

Phone: +34 660062066 ,

E-mail: fegarpi@gmail.com

Manuscript submitted on February 24, 2014

Manuscript accepted on August 4, 2014



Motriz. The Journal of Physical Education. UNESP. Rio Claro, SP, Brazil - eISSN: 1980-6574 - under a license Creative Commons - Version 3.0 